\title{
INVESTIGATING LIBYAN CONSUMERS' ACCEPTANCE TOWARDS GREEN PURCHASING CONCEPT
}

\author{
Abdulsatar Fathe G. Il Tohame ${ }^{a)}$, Genoveva, Genoveva ${ }^{\left.a^{*}\right)}$ \\ a) President University, School of Business, Bekasi, Indonesia \\ *)Corresponding Author: genoveva@president.ac.id
}

Article history: received 09 January 2021; revised 13 February 2021; accepted 26 February 2021

\begin{abstract}
Green purchasing concept adoption witnessing a rapid increase according to recent researches, not to mention that, environmental issues have been trending in the last few decades as well, and according to previous researches, a lack of literatures regarding this issue in Libya were found after searching around the country's biggest universities such as Tripoli University, Benghazi University, and Misurata University. This study used quantitative research method aiming to investigate the strongest variables affecting the Libyan consumers' acceptance towards the concept of green purchasing among three different categories of variables, environmental knowledge, cultural beliefs and price sensitivity, as Libya is showing a very slow growing in adopting the concept of green purchasing, hence, conducting such a study is an essential role-play in highlighting the strongest factors affecting the adoption of the concept amongst Libyan consumers. The data was collected via distributed Google form, and a sample of 700 respondents were collected to be analyzed using SPSS 0.25 . Accordingly, findings showed the significant affect that environmental knowledge and cultural beliefs severally have on Libyan consumers' acceptance towards green acceptance, at a variance to price sensitivity which showed insignificant effect. Moreover, environmental knowledge, cultural beliefs and price sensitivity concurrently affected the acceptance of Libyan consumers' acceptance towards green purchasing.
\end{abstract}

Keywords: green purchasing acceptance, environmental knowledge, cultural beliefs, price sensitivity

\section{INTRODUCTION}

Among Mediterranean countries that having a noticeable adopting to the concept of converting into proenvironmental lifestyle, Libya is going slower than all these Mediterranean countries, and on the top of those issues regarding the relation of the Libyan society with their environment is pollution as the biggest threat which was fundamentally noticed in different cities (Del Sarto et al., [1]). Different types of environmental issues been globally observed, such as climate change, increasing the sea level, including the three categories of pollution as well, water, land, and air pollution. Overall the problem is certainly difficult to reach an end, unless the consumers started practicing more of pro-environmental procurements to minimize the environmental degradation (Nezakati \& Hosseinpour [2]). A general introduction with the aim of defining green purchasing, that it is all the affirmative purchasing actions and behaviors of services and products, in order to minimize the negative environmental impacts of those acquisitions, while consuming, after purchasing effects as well as during the transportation process of those products and services, even while recycling or disposal (Dubey et al. [3]).

(Vazifehdoust et al. [4]) also defined Green buying behaviors, consumers are increasingly aware of the tremendous influence their buying behavior could have on the environment. (Dagher \& Itani, [5]) found that by exhibiting green buying actions, customers are seeking to help preserve their ecosystem. Studies been world widely conducted investigating and analyzing the response of consumers to their culture, and to their awareness or deep knowledge of a specific concept before the process of purchasing. Globally, green purchasing is a familiar concept, despite the fact that it differs from a country to another, and such differences occur as a result of the cultural diversity between countries, including a very important indicator that highlights the awareness and the knowledge individuals have regarding the damages of some purchasing processes.

Environmental knowledge helps in guiding local and foreign investors in making their green marketing campaigns. Therefore, this variable was an essential choice in this research. Furthermore, Integrating the selected variables together into one model is giving more clearer vision on the Libyan consumers' green purchasing behaviors. (Genoveva [6]) defined environmental knowledge as" knowing the effect on the environment of human behavior and purchases on purchasing a consuming process. Environmental knowledge has both a semantic dimension based on experience, and an affective component, based on interpretation, environmental perception is limited by many emotional and cognitive influences. The more consumers know about their community and environmental problems, the more they become interested in pro-environmental behavior (Sharaf \& Perumal [7]).

Occasionally, cultural influences on buying behaviors can be obviously noticed. It is possible to explain certain purchasing habits through cultural bans against eating items such as alcohol or beef, or cultural expectations for clothing types. Culture can also have either a positive or a negative 
effect on green purchases behaviors. Additionally, and in terms of empirical implication, understanding the sensitive role of cultural values is essential to determine the level of influence and how important to analyze any developing country's culture (Lee \& Kacen [8]).

Price is an essential influencer on purchasing decision behavior, whether those purchases were green or regular ones (Albari \& Safitri [9]). Elshween doctor in Environmental science (Interview [10]), and the Head of Environmental Inspection office in Tripoli, Libya, all the green products in the Libyan market are being sold at a very high price, and consumers have a problem with understanding the value of these pro-environmental products, because of their high price. Additionally, traders and entrepreneurs have to play a role in encouraging Libyans to a greener life. In addition, Dr. Elshween stated.

In United Arabs of Emirates (UAE) a study declared the influence of green products prices, and it was revealed by the authors that the prices of pro-environmental products ranked as the highest critical factor impacting the proenvironmental behaviors, and available green products at high prices force consumers' behaviors renitent to green procurements regardless how beneficial they were (Al Nuaimi et al.[11]).

\section{Problem Statement}

As an illustration of the problem, a previous survey conducted to investigate the household recognition of the rate of usable energy of their house appliances, and resulted that $91 \%$ do not know the amount of energy wasted by the extra use of those appliances, this problem is a long-standing challenge for Libyan community (Mohamed et al. [12]).

\section{Are you aware of your household appliances energy rang?}

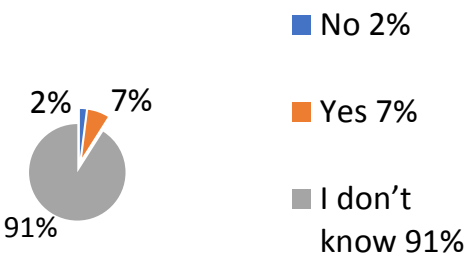

Fig. 1 Libyan Households Awareness of the rating of their household appliances consuming. (Mohamed et al. [12]).

Local environmentalists including people from different ages and occupations, in Morocco, Algeria, Tunisia, Egypt, and Jordan, including other countries around MENA in a partnership with Greenpeace MENA have been calling for protests collecting thousands of participants asking for a greener climate and style of living (Greenpeace Org [13]).

Environmental concerns are partly taking place in our daily life purchases. Notwithstanding, that the pro- environmental purchasing behaviors have been investigated in Western countries, researchers have recommended future works investigating the concept of pro-environmental behaviors in developing countries (Joshi \& Rahman [14]).

In general, the North African region is also at risk of arable land depletion and intensified coastal erosion, driven primarily by inefficient farming activities and unmanaged competition for land and sea resources. Due to 10 Libyan Environmental Laws and Problems, permanent cropland, actually less than $6 \%$ of the overall land area and less than $1 \%$ in Libya, is declining in the MENA countries as a whole due to severe land loss and frequent droughts.

This study is previewing the testimony of 700 Libyan citizens who were randomly collected from Libyan social media famous groups, such an investigation will declare the perceiving of high context culture society of green purchasing concept, and which among the selected variables affects the acceptance of Libyan consumers' acceptance towards Green Purchasing concept. As a consequence, marketers of this region will have to consider whether the green marketing campaigns in Libya are effectively having a positive response from the targeted market or not.

After searching the previous literatures regarding the acceptance of the Libyan society to the Green purchasing concept, no studies were found at the main three universities in the country, Tripoli, Misurata, and Benghazi University. Accordingly, this was the motivator to investigate the dimensions of accepting the green purchasing concept among Libyans.

\section{Research Gap}

Although some attempts have been made to address this issue, it is still measurable to highlight the strongest factors affecting the lack of accepting the Libyan consumers towards the concept of green purchasing. Mohamed et al. [12] have shown that there is a very high consumption of energy from Libyan householders, without highlighting the main factors suggesting that government is required to take an action towards a green consumption from householders, the need arose due to issues with the their research that they highlighted the consuming of home appliance without generally studying the acceptance of green purchasing among Libyan consumers, since home appliance industry might have other factors affecting it. Another study conducted on Indian consumers aiming to increase their proenvironmental purchases, Libya is a developed country as well as India, however, since both of them located in two different continents, cultural values and environmental knowledge can have different affects. For that reason, this study warrants a better and clearer understanding of the acceptance of Libyan consumers towards green purchasing concept in general without any determination of the industry or specific kind of products, including considering the Libyan norms and cultural beliefs.

\section{Green Purchasing}

Green purchasing is, the matrix of behaviors and purchasing operations in order to conserve the natural 
resources and the protecting the environment and individual lives in a nation, and reaching the sustainability at any society according to (Panjaitan \& Sutapa [15]). Green purchasing takes place when buyers try to help their environment, and society avoiding the effects of their purchasing behaviors (Genoveva [6]). Consuming green products and services is an essential and trendy literature among the different marketing researches, especially in Western countries (Nguyen et al.[16]). Recently, in Pakistan, the government realized that it is very important to understand the priority of motivating consumers to consume more green products and services (Hashim et al. [17]).

The importance of environmental issues reaches the highest authorities of countries, that many governments and organizations trying to protect the environment by preparing laws and regulations (Vazifehdoust et al.[4]).

\section{Environmental Knowledge}

Environmental knowledge is the process of appreciation of the "whole environmental system" and the knowledge people have about the surrounded environment, involving them to be responsible and of their actions impacts on the environment (Genoveva [6]).

Joshi \& Rahman [14] Found that one of the strongest influencers on pro-environmental procurements is a high level of individuals' environmental knowledge, and consumers with a high environmental knowledge are aware of the damages. Having a complete knowledge regarding side and the direct effects of the purchased products (Tong et al.[18]). Kumar et al. [19] analyzed the influence of environmental knowledge on young Indian consumers' green purchasing behaviors using TPB model, the findings showed that, the most important factors impacting the green behaviors of young Indians were norms, and environmental knowledge. In Turkey, a sample of 410 consumers based in Gaziantep city was analyzed to investigate what factors might be affecting, resulting that consumers' green acquisitions are affected by environmentalism and knowledge the most (Seyrek \& Gul, [20]). Environmental knowledge is essential according to vast of literatures, and as an empirical Libyan study, it was investigated that, the main reason of home appliance usage increase is the lack of knowledge of Libyan householders (Mohamed et al[12]). Malaysian government invests a lot in protecting the environment against the harmful purchasing operations taking place in the country. Sustainable development level depends on peoples' knowledge about the system as a whole, their appreciation of the environmental system is based on how well do they know about it. And according to Genoveva [6] pro-environmental products purchasing intention is significantly influenced by the knowledge of the consumers.

\section{Cultural Beliefs}

Culture is where different groups of people will vary from their way of behaving and style of living motivated by norms, beliefs and sometimes religious teachings. Cultures differ from a society to another, that variously reflecting on consumers'purchasing behaviors in general, and green purchases in specific. Green purchasing acceptance and attitude is created by social interaction supported by knowledge. The dimension of culture has always been an essential highlighter for consumer behavior, and there have been a great number of studies examining the impact of culture on the green purchasing behavior of consumers. (Sreen et al.[21]) found that norms, and cultural beliefs can be a good indicator for policy-makers and marketers to increase the green purchasing intention. (Mohamed et al[12]) and (Chwialkowska et al.[22]). discussed that, decreasing the consumption of home appliance among Libyan householders, depends on their cultural beliefs and norms, and the consumption will be lessen by $10-30 \%$ for every week. There have been several attempts to the important role that culture of individuals plays in dealing with different environmental issues. A recent systematic review investigated the importance of culture in building the environmental intentions of consumers and directing their behaviors in addition, however, scholars' knowledge of how cultural values make that influence is still limited.

\section{Price Sensitivity of Green Products}

Prices, as the terminology used in economics and financial domains, is the amount or the value for a product or a service. In other words, pricing occurs when a business decides how much a customer must pay for a product or service (Rana \& Paul [23]). Using an eco-friendly lighting bulb is not a common Libyan behavior, and there was a lack of literatures according to this regarding this issue. However, Mohamed et al [12] discussed that Libyan householders' main problem is the price of the eco-friendly bulbs and products in general. Suggesting that, the government should make decisions limiting the huge increase of the green products in the country. In 2014, pro-environmental automobiles acceptance by Malaysian consumers was investigated resulting that, accepting the new green technology has to be based on two main factors as the study highlighted. Environmental benefit. And, the cost of the green products should be attainable and acceptable, because consumers will defiantly compare it with other regular products according to the comparative cost concept (Mansor et al. [24]). Conceptually identical work, utilising a similar framework, was proposed by Zhao \& Wu, [25], after measuring several factors such as income level, price, lifestyle, purchase experience, health consciousness, the results showed a positive relation between all the factors and the consumer purchasing behaviors of organic food in Harbin, except for the Price factor which obtained a negative relationship among all the other factors. In China and India, researchers observe that quality standing side by side with price are still the main primary influencers of any individual's purchasing decision whether it was a normal or green purchasing decision. Therefore, reasonable price serves the target of increasing green products purchases (Patnaik et al. [26]). In an Iranian province (Guilan), Akehurst et al. [27]) claimed that in that province the intention of buying green products is increasing even though they are usually quite more expensive than regular products. 
This has been questioned by some and others suggest that the more expensive green products become the less the intention of buying them becomes.

\section{Consumers' Acceptance towards Green Products}

Taking a further step towards the future of greener technological purchasing behavior was the target of (Mansor et al. [24]) study, for the purpose of this study, the researchers wanted to reach the fact whether Malaysian consumers espouse the concept of green purchasing and providing a future insight of green purchasing behaviors through vehicles industry, the findings reinforce the general belief that the Malaysian consumers acceptance of the concept is still unambitious.

Developed countries have been an interest for a considerable period. A study conducted in India by (Mishal et al.[28]), the study is often constructed for a number of reasons, however the main purpose is to reach a strategy for extending the pro-environmental purchasing concept among Indian consumers.

\section{Theoretical Framework}

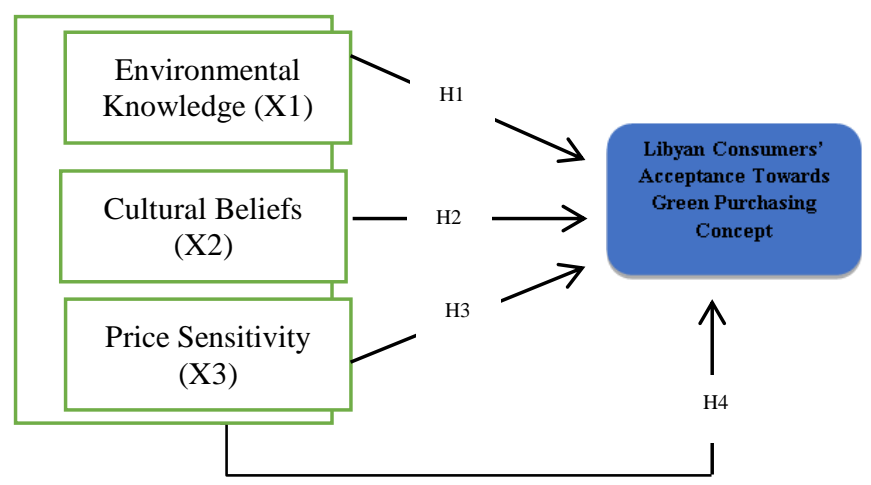

Figure 2. Theoretical framework Adopted from (Mansor et al. [24]) and (Genoveva [6])

Fig. 2 shows the variables' relations with the investigated main concept of the study. Whereas, hypothesis (1) indicates the relationship between environmental knowledge (X1) and the acceptance of Libyan consumers' towards green purchasing (Y), and hypothesis (2) shows its relation with cultural beliefs (X2). Lastly (X3) shows the relationship between price sensitivity and the acceptance of Libyan consumers towards green purchasing.

\section{Hypothesis Development}

H1: There is a significant effect of Environmental knowledge on Libyan consumers' acceptance towards green purchasing.

H2: There is a significant effect of Cultural beliefs on Libyan consumers' acceptance towards green purchasing.

H.3: There is a significant effect of products' prices on Libyan consumers' acceptance towards green purchasing.
H.4: Environmental knowledge, cultural beliefs, and price sensitivity simultaneously affect the Libyan consumers' acceptance towards green purchasing.

\section{RESEARCH METHODS}

This study evaluates an object and analyzes the effect of the independent and dependent variables, partially and simultaneously, teherefore, the design of this study is quantitative. The sampling technique used is non-probability sampling. Data is collected through online questionnaires, google forms which are distributed through social media. The responses to this questionnaire was very good, where the researchers got 700 respondents, exceeding the target we set, namely 150 respondents. Data were processed using SPSS version 25.

\section{RESULTS AND DISCUSSION}

\section{Reliability of questions}

Table 1. Coronbach's alpha of the used questions for each variable.

\begin{tabular}{|c|l|c|c|}
\hline No & \multicolumn{1}{|c|}{ Variable } & $\begin{array}{c}\text { Cronbach's } \\
\text { alpha }\end{array}$ & $\begin{array}{c}\text { Number } \\
\text { of items }\end{array}$ \\
\hline $\mathbf{1}$ & Environmental Knowledge (X1) & 0.934 & 9 \\
\hline $\mathbf{2}$ & Cultural Beliefs (X2) & 0.764 & 6 \\
\hline $\mathbf{3}$ & Price (X3) & 0.732 & 6 \\
\hline $\mathbf{4}$ & $\begin{array}{l}\text { Libyan Consumers' Acceptance } \\
\text { Towards Green Purchasing (Y) }\end{array}$ & 0.822 & 6 \\
\hline
\end{tabular}

Measuring the reliability of a phenomenon's value of Cronbach's alpha coefficient which has to be greater than 0.6 for every variable from the tested variables (Ursachi et al. [29]). And as the following table shows that Cronbach's alpha coefficient of all variables resulted higher than (0.6) as it is shown in Table 1.

\section{Validity of questions}

Table. 2 Validity of environmental knowledge (EK) statements.

\begin{tabular}{ccccc}
\hline Variable & Questions & R-table & R & Decision \\
\hline & EK1 & 0.361 & 0.880 & Valid \\
& EK2 & 0.361 & 0.766 & Valid \\
& EK3 & 0.361 & 0.888 & Valid \\
Environmental & EK4 & 0.361 & 0.714 & Valid \\
Knowledge & EK5 & 0.361 & 0.430 & Valid \\
(EK) & EK6 & 0.361 & 0.879 & Valid \\
& EK7 & 0.361 & 0.959 & Valid \\
& EK8 & 0.361 & 0.889 & Valid \\
& EK9 & 0.361 & 0.894 & Valid \\
\hline
\end{tabular}

Table. 3 Validity of cultural beliefs (CB) statements.

\begin{tabular}{ccccc}
\hline Variable & Questions & R-table & R & Decision \\
\hline & CB1 & 0.361 & 0.578 & Valid \\
& CB2 & 0.361 & 0.815 & Valid \\
Cultural & CB3 & 0.361 & 0.674 & Valid \\
Beliefs (CB) & CB4 & 0.361 & 0.772 & Valid \\
& CB5 & 0.361 & 0.702 & Valid \\
& CB6 & 0.361 & 0.523 & Valid \\
\hline
\end{tabular}


Table. 4 Validity of price sensitivity $(\mathrm{P})$ statements.

\begin{tabular}{ccccc}
\hline Variable & Questions & R-table & R & Decision \\
\hline \multirow{4}{*}{ Price } & P1 & 0.361 & 0.882 & Valid \\
& P2 & 0.361 & 0.632 & Valid \\
Sensitivity (P) & P3 & 0.361 & 0.588 & Valid \\
& P4 & 0.361 & 0.599 & Valid \\
& P5 & 0.361 & 0.697 & Valid \\
& P6 & 0.361 & 0.624 & Valid \\
\hline
\end{tabular}

Table. 5 Validity of Consumers' acceptance $(\mathrm{Y})$ statements.

\begin{tabular}{ccccc}
\hline Variable & Questions & R-table & R & Decision \\
\hline Libyan & Y1 & 0.361 & 0.618 & Valid \\
Consumers' & Y2 & 0.361 & 0.623 & Valid \\
Acceptance & Y3 & 0.361 & 0.804 & Valid \\
Towards & Y4 & 0.361 & 0.801 & Valid \\
Green & Y5 & 0.361 & 0.713 & Valid \\
Purchasing & Y6 & 0.361 & 0.792 & Valid \\
(Y) & & & & \\
\hline
\end{tabular}

Predicting the validity of your questions is a test is a process or analysis of differentiating the valid questions in a questionnaire from the invalid ones, and Pearson's Correlation Coefficient can be used to indicate the valid questions in any questionnaire, the values of Pearson's Correlation Coefficient (R) which measure the valid questions have to be higher than $(0.361)$ which represents the value of critical value of (R-table), the test was conducted after distributing (30) samples for testing the validity of the questionnaire (Mohamad et al. [30]).

Noticeably, in table $(2,3,4$, and 5$)$ all the $(\mathrm{R})$ values are greater than (R-table) values. Accordingly, all the questions were tested valid to continues distributing the questionnaire.

\section{Descriptive Statistics Analysis Results}

Table. 6. Descriptive Statistics Analysis Results

\begin{tabular}{cccc}
\hline Variable & N & Mean & $\begin{array}{c}\text { Std. } \\
\text { Deviation }\end{array}$ \\
\hline $\begin{array}{c}\text { Environmental } \\
\text { Knowledge (X1) }\end{array}$ & 700 & 3.92 & 0.84 \\
Cultural Beliefs (X2) & 700 & 3.54 & 0.94 \\
$\quad$ Price (X3) & 700 & 3.08 & 0.98 \\
$\begin{array}{c}\text { Libyan Consumers' } \\
\text { Acceptance of Green } \\
\text { Purchasing (Y) }\end{array}$ & 700 & 4.19 & 0.79 \\
\hline
\end{tabular}

Table. 6 shows the determination of which variable is the most dominant among the three dependant variables of research in association with Libyan consumers' Acceptance toward green purchasing (Y), table 6 shows that Environmental knowledge is the most dominant variable at 3.92 , where the least associated variable is Price at 3.08 .

\section{Normality Tes}

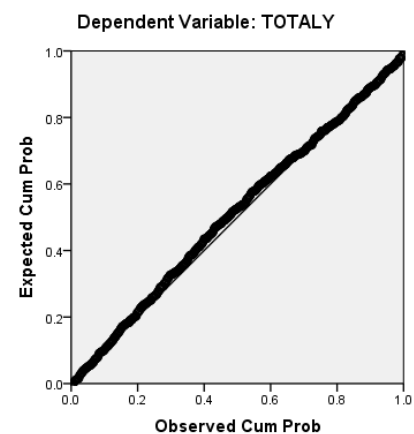

Figure. 3 P-P Plot Test

Normality test can be visualized using Normal P-P plot test and Histograms, and on the other side Heteroscedasticity test can be visualized by using Scatter Plots test.

\section{Normality Test (Histogram)}

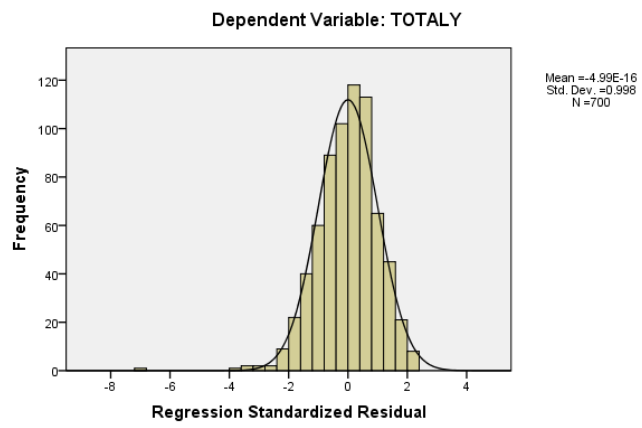

Figure: 4 (Histogram) Normality Test

According to the noticeable spreading of the data in Figure 3 and 4, we can say that the data is normally spreading and indicating to a normal distribution.

\section{Multicollinearity Test}

Suitable regression of a study have to be obtained showing a low rate of Multicollinearity, where variables have to obtain a lack of (VIF) and tolerance level to be suitable and away from redundancy of the information, where the tolerance values of the variables have to be $<0.1$, and $(\mathrm{VIF})$ values have to be $(\mathrm{VIF}>10)$ (e.g. Table. 6)

Table. 7 DependentVariable: TOTALLY

Coefficients $^{\mathbf{a}}$
\begin{tabular}{|rr|r|r|}
\hline \multirow{2}{*}{ Model } & \multicolumn{2}{|c|}{ Collinearity Statistics } \\
\cline { 2 - 4 } & & Tolerance & \multicolumn{1}{c|}{ VIF } \\
\hline 1 & (Constant) & & \\
& TOTALEK & .959 & 1.042 \\
& TOTALCB & .912 & 1.096 \\
& & .941 & 1.063 \\
\hline
\end{tabular}


Hypotheses Result

Table. 8 Multiple Regressions Results

\begin{tabular}{lccccc}
\hline \multirow{2}{*}{ Model } & \multicolumn{2}{c}{$\begin{array}{c}\text { Unstandardized } \\
\text { Coefficients }\end{array}$} & $\begin{array}{c}\text { Standardized } \\
\text { Coefficients }\end{array}$ & $\mathbf{t}$ & Sig. \\
\cline { 2 - 4 } & $\mathrm{B}$ & $\begin{array}{c}\text { Std. } \\
\text { Error }\end{array}$ & Beta & & \\
\cline { 2 - 4 } (Constant) & 11.188 & 1.223 & & & \\
TOTX1 & .234 & .028 & .292 & 8.145 & .000 \\
TOTX2 & .209 & .032 & .235 & 6.554 & .000 \\
TOTX3 & .069 & .042 & .058 & 1.641 & .101 \\
\hline
\end{tabular}

From the previous table, we can notice that all variables are significant as their $(\mathrm{p}<0.05)$ excluding $(\mathrm{X} 3)$ Price that obtained $(\mathrm{P}>0.05)$. This means that only Environmental knowledge and Cultural beliefs have a significant positive influence on respondents' Acceptance towards Green Purchasing. As a result, the model can be modified further in the equation.

\section{Where:}

Y is Libyan Consumers' Acceptance Towards Green

Purchasing Concept

TOTX1 is Environmental Knowledge

TOTX2 is Cultural Beliefs

TOTX3 is Price

$\beta 0$ is Constant (11.188)

\section{Equation}

$$
\mathrm{Y}=\mathbf{1 1 . 1 8 8}(\text { Constant })+\mathbf{0 . 2 3 4}(\mathrm{X} 1)+\mathbf{0 . 2 0 9}(\mathrm{X} 2)
$$

As the (X3) value of Sig. is 0.101 as in table 8, therefore, it has to be excluded from the equation as this variable has no significant influence on the dependent variable.

T-test

T-test is generally implemented to highlight the significant effect of each independent variable on the dependent variable (Libyan Consumer's Acceptance Towards Green Purchasing). Significances of variables to be determined if $\mathrm{P}$ value is less than 0.05 .

\section{Environmental Knowledge (X1) effect on Libyan} Consumers' Acceptance

Ho.1: There is no significant effect of environmental knowledge on Libyan consumers' acceptance towards green purchasing.

Ha.1: There is a significant effect of environmental knowledge on Libyan consumers' acceptance towards green purchasing.

According to the $(\mathrm{P})$ value of Environmental knowledge in table 8 . we can conclude that we fail to accept the null hypothesis, where Environmental knowledge obtained (0.000), as a result, at $(\mathrm{P}<0.05)$ value we assume that the alternative hypothesis (Ha.1) stating that environmental knowledge has a significant effect on Libyan consumers' acceptance towards green purchasing.

\section{Cultural Beliefs (X2) effect on Libyan Consumers' Acceptance}

Ho.2: There is no significant effect of cultural beliefs on Libyan consumers' acceptance towards green purchasing.

Ha.2: There is a significant effect of Cultural beliefs on Libyan consumers' acceptance towards green purchasing.

According to the $(\mathrm{P})$ value of Cultural beliefs in table 8 . we can conclude that we fail to accept the null hypothesis, where Cultural beliefs obtained $(0.000)$, as a result, at $(\mathrm{P}<0.05)$ value we assume that the alternative hypothesis (Ha.1) stating that Cultural beliefs has a significant effect on Libyan consumers' acceptance towards green purchasing.

3. Price (X3) effect on Libyan Consumers' Acceptance Ho.3: There is no significant effect of products' Prices on Libyan consumers' acceptance towards green purchasing Ha.3: There is a significant effect of products' Prices on Libyan consumers' acceptance towards green purchasing.

According to the $(\mathrm{P})$ value of Price in table 8 which was $(\mathrm{P}>0.05)$, we can conclude that we to accept the null hypothesis, the obtained $\mathrm{P}$ value was (0.101).

\section{F-Test}

Ho.4 Environmental knowledge, cultural beliefs, and price do not simultaneously influence the Libyan consumers' acceptance towards green purchasing.

Ha.4 Environmental knowledge, cultural beliefs, and prices simultaneously influence the Libyan consumers acceptance towards green purchasing.

If the F Value < F Table, Ho.4 accepted and Ha.4 rejected. If the $\mathrm{F}$ Value > F Table then Ho.4 rejected and Ha.4 accepted.

If the $\mathrm{P}$ Value $<0.05$, Ho.4 accepted and Ha.4 rejected. If the $\mathrm{P}$ Value $>0.05$, Ho. 4 rejected. and Ha. 4 accepted.

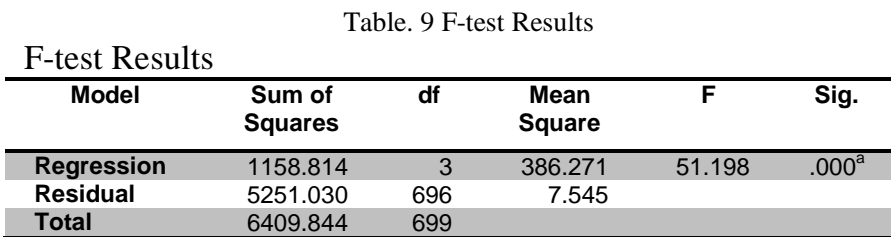

According to (table. 9) Respondents of this research were 700 people in total, and the used variables were 3 at a significant level of (0.05). Therefore, dfb will be 2 as (3-1), and the value of dfw will be 697 calculated as (700-3), total number of respondents minus the number of independent variables.

Furthermore, $\mathrm{F}$ critical value according to (Appendix table) will be (2.61), which is less than $\mathrm{F}$ value in table 9 which was $(51.198)$. In parallel, $P$ value $(0.000)$ which means we can confirm the form $(\mathrm{P}<0.05)$. Thence, the null hypothesis is declined, and we assume the alternative 
hypothesis stating that (Environmental Knowledge, Cultural Beliefs, and Price) simultaneously affect the Libyan consumers' acceptance towards green purchases.

\section{Results interpretation}

Table. 10 Hypothesis Result

\begin{tabular}{|c|c|c|}
\hline Hypothesis & Sig. & Conclusion \\
\hline $\begin{array}{l}\text { Environmental knowledge } \longrightarrow \\
\text { Libyan Consumers' Acceptance of } \\
\text { Green Purchasing }\end{array}$ & 0.000 & Sign \\
\hline $\begin{array}{l}\text { Cultural beliefs } \longrightarrow \\
\begin{array}{l}\text { Consumers' Acceptance } \\
\text { Purchasing }\end{array}\end{array}$ & 0.000 & ficant \\
\hline $\begin{array}{l}\text { Price sensitivity } \longrightarrow \text { Libyan } \\
\text { Consumers' Acceptance of Green } \\
\text { Purchasing }\end{array}$ & 0.101 & $\begin{array}{l}\text { No } \\
\text { Significant }\end{array}$ \\
\hline $\begin{array}{l}\text { Environmental knowledge, Cultural } \\
\text { beliefs and Price } \stackrel{\text { Libyan }}{\longrightarrow} \text { Len } \\
\text { Consumers' Acceptance of Green } \\
\text { Purchasing }\end{array}$ & 0.000 & Significant \\
\hline
\end{tabular}

Environmental Knowledge on Libyan Consumers' Acceptance of Green Purchasing.

The effect of environmental knowledge is noticeable, and it has a very strong relation with the consumers' acceptance as it obtained 0.000 smaller than (0.05) lower than beta coefficient. This was similarly summarized by other literatures such as Vazifehdoust et al. [4] who stated that environmental knowledge is a key relationship to obtain a whole system environmental improvement, and leading to a greener style of purchasing. The involvement of the environmental knowledge in having a more significances effect on consumers green life and purchases was declared and confirmed in previous literatures according to (Genoveva [6] ).

\section{Cultural Beliefs on Libyan Consumers' Acceptance of Green} Purchasing

The effect of Cultural Beliefs is noticeable, and it has a very strong relation with the consumers' acceptance as it obtained 0.000 smaller than (0.05) lower than beta coefficient. Previous researches showed to role of culture in directing the purchasing behaviour of consumers. Culture played a great role in influencing the purchases of consumers in different countries. However, its effect varies from region to another, as it was investigated among Malaysian citizens and came with a contrast with this research that culture has the least significant between all other variables, not to mention that in the same research the author showed the significance of culture among Nigerian citizens and its importance in motivating Nigerians to become greener consumers (Ogiemwonyi et al. [31]).

\section{Price sensitivity on Libyan Consumers' Acceptance of Green} Purchasing.

The effect of Price is unnoticeable, and it has a very strong relation with the consumers' acceptance as it obtained 0.101 greater than (0.05) lower than beta coefficient.
Accordingly, we can conclude that Price has no significant impact on Libyans acceptance towards green purchasing concept. A comparative study between brand image and price effect on purchasing decision in Indonesia showed that brand image is more significant than price according to 166 respondents in a research by (Albari \& Safitri [9]). Price has been noticed to be an effective variable in different researches, however, it was considered that green products manufacturers should consider price as well as environmental benefits (Mansor et al. [24]).

Environmental knowledge, Cultural beliefs and Price sensitivity on Libyan Consumers' Acceptance of Green Purchasing

The three variables together (Environmental knowledge, Cultural beliefs and Price) have a combined significant effect on the Libyan consumers' acceptance towards the concept of purchasing green products and services. Price is possible factor that might affect any consumer's decision when it comes to purchasing a green product, addition, environmental knowledge and concerns supported with social norms and beliefs would definitely have a significant effect on consumers' green purchasing decisions (Patnaik et al. [26]). Thence, the results of this hypothesis test can be classified as significant at a value $(<0.05)$

\section{CONCLUSION}

This part of the research contains the last summarized version of this research's results. Where I will be previewing the analysis findings from the resulted relations between the independent variables (environmental knowledge, cultural beliefs, and price) towards the dependent variable represented by the Libyan consumer's acceptance towards green purchasing.

The findings to be discussed as follow;

1- Environmental knowledge has a significant effect on Libyan consumer's acceptance towards green purchasing

2- Cultural beliefs has a significant effect on Libyan consumer's acceptance towards green purchasing

1. Price sensitivity has No significant effect on Libyan consumer's acceptance towards green purchasing

2. Environmental knowledge, cultural beliefs, and price sensitivity has a significant effect on Libyan consumer's acceptance towards green purchasing, since the $F$ value is 51.198 and greater than the critical value came at 2.61.

Researhers would recommend to analyze more variables as the variables showed only $17 \%$ percentage of influencing the dependent variable, and maybe researchers can select a specific community such as university students or maybe a specific social class to be researched. I recommend that Libyan government takes a step further in promoting the environmental knowledge via educational environmental advertises and school workshops for students of different ages. Researhers would also recommend that Libyan universities stop ignoring this essential topic, additionally, more methodologies can be implemented in the 
field e.g. qualitative or mixed method quantitativequalitative method in order to obtain different results and conducting different tests analyzing further relations between the variables.

\section{REFERENCES}

[1] Del Sarto, R. A., Malmvig, H., \& Lecha, E. S. i. 2019. Interregnum: The Regional Order in the Middle East and North Africa after 2011. SSRN Electronic Journal, 1, 1-58.

[2] Nezakati, H., \& Hosseinpour, M. 2015. Green Products Purchasing Among Malaysian Consumers. International Journal of Sustainable Development \& World Policy, 4(1), 1-6. https://doi.org /10. 18488/ journal.26/2015.4.1/26.1.1.6

[3] Dubey, R., Bag, S., Ali, S. S., \& Venkatesh, V. G. 2013. Green purchasing is key to superior performance: An empirical study. International Journal of Procurement Management, 6(2), 187-210. https://doi.org/10.1504/IJPM.2013.052469

[4] Vazifehdoust, H., Taleghani, M., Esmaeilpour, F., Nazari, K., \& Khadang, M. 2013. Purchasing green to become greener: Factors influence consumers' green purchasing behavior. Management Science Letters, 3, 2489-2500.

https://doi.org/10.5267/j.msl.2013.08.013

[5] Dagher, G. K., \& Itani, O. 2014. Factors influencing green purchasing behaviour: Empirical evidence from the Lebanese consumers. Journal of Consumer Behaviour, 13(3), 188-195.

https://doi.org/10.1002/cb.1482

[6] Genoveva. 2016. Factors affecting consumers' green purchase behavior (an empirical study of indonesia pay plastic policy). 10(2), 31-36.

[8] Lee, J. A., \& Kacen, J. J. 2008. Cultural influences on consumer satisfaction with impulse and planned purchase decisions. Journal of Business Research, 61(3), 265-272.

https://doi.org/10.1016/j.jbusres.2007.06.006

[7] Sharaf, M. A., \& Perumal, S. 2018. How does Green Products' price and availability impact Malaysians' green purchasing behavior? Journal of Social Sciences Research, 4(3), 28-34.

[9] Albari, \& Safitri, I. 2018. The influence of product price on consumers' purchasing decisions. Review of Integrative Business and Economics Research, 7(2), 328-337.

[10] Interview (Dr. Elshween) Inspector of environmental office in Tripoli-Libya

[11] Al Nuaimi, B. K., Khan, M., \& Ajmal, M. 2020. Implementing sustainable procurement in the United Arab Emirates public sector. Journal of Public Procurement, 20(2), 97-117. https://doi.org/10.1108/JOPP-07-2019-0044

[12] Mohamed, A. M. A., Al-Habaibeh, A., Abdo, H., \& Elabar, S. 2015. Towards exporting renewable energy from MENA region to Europe: An investigation into domestic energy use and householders' energy behaviour in Libya. Applied Energy, 146, 247-262. https://doi.org/10.1016/j.apenergy.2015.02.008

[13] Greenpeace Org. 2020. Greenpeace Middle East and North Africa guidelines regarding emissions, smoke and dust rising from the explosion that occurred in the Beirut port on August 4, 2020 Greenpeace MENA. https://www.greenpeace.org/mena/ar/إرشادات /منظمة_غرينبيس-الثرق-الأوسطـوش

[14] Joshi, Y., \& Rahman, Z. 2015. Factors Affecting Green Purchase Behaviour and Future Research Directions. In International Strategic Management Review (Vol. 3, Issues 1-2). Holy Spirit University of Kaslik. https://doi.org/10.1016/j.ism.2015.04.001

[15] Panjaitan, T. W. S., \& Sutapa, I. N. 2010. Analysis of green product knowledge, green behavior and green consumers of Indonesian students (case study for universities in Surabaya). IEEM2010 - IEEE International Conference on Industrial Engineering and Engineering Management, August 2015, 22682272. https://doi.org/10.1109/IEEM.2010.5674276

[16] Nguyen, H. V., Nguyen, C. H., \& Hoang, T. T. B. 2019. Green consumption: Closing the intentionbehavior gap. Sustainable Development, 27(1), 118129. https://doi.org/10.1002/sd.1875

[17] Hashim, M., Baig, S. A., Abrar, M., Afzal, A., \& Mohsin, M. 2019. Effects of Green Marketing on Green Purchase Intentions. Dialogue (1819-6462), 14(2), 266-278. http://search.ebscohost.com/login. Aspx?direct $=$ true $\& d b=a 9 h \& A N=138407715 \&$ lang $=e$ s\&site $=$ ehost-live

[18 Tong, Q., Anders, S., Zhang, J., \& Zhang, L. 2020. The roles of pollution concerns and environmental knowledge in making green food choices: Evidence from Chinese consumers. Food Research International, 130, 108881. https://doi.org/10.1016/j.foodres.2019. 108881

[19] Kumar, A., Prakash, G., \& Kumar, G. 2021. Does environmentally responsible purchase intention matter for consumers? A predictive sustainable model developed through an empirical study. Journal of Retailing and Consumer Services, 58 https://doi.org/10.1016/j.jretconser.2020.102270

[20] Seyrek, I. H., \& Gul, M. 2017. Factors Affecting Green Purchasing Behavior: A Study of Turkish Consumers. International Journal of Academic Research in Business and Social Sciences, 7(1). https://doi.org/10.6007/ijarbss/v7-i1/2607

[21] Sreen, N., Purbey, S., \& Sadarangani, P. 2018. Impact of culture, behavior and gender on green purchase intention. Journal of Retailing and Consumer Services, 4l(July 2017), 177-189. https://doi.org/10.1016/j.jretconser.2017.12.002

[22] Chwialkowska, A., Bhatti, W. A., \& Glowik, M. 2020. The influence of cultural values on proenvironmental behavior. Journal of Cleaner Production, 268, 122305. 
https://doi.org/10.1016/j.jclepro. 2020.122305

[23] Rana, J., \& Paul, J. 2017. Consumer behavior and purchase intention for organic food: A review and research agenda. Journal of Retailing and Consumer Services, 38(February), 157-165. https://doi.org/10.1016/j.jretconser.2017.06.004

[24] Mansor, N., Yahaya, S. N., Nizam, N. Z., \& Hoshino, Y. 2014. Consumers' Acceptance towards Green Technology in Automotive Industries in Malacca, Malaysia. International Journal of Business Administration, 5(1). https://doi.org/10.5430/ijba.v5n1p27

[25] Zhao, D., \& Wu, M. 2016. Research on the influencing factors of consumer purchase behavior of green food in harbin. Proceedings of the 28th Chinese Control and Decision Conference, CCDC 2016, 4479-4482. https://doi.org/10.1109/CCDC.2016.7531791

[26] Patnaik, A., Sahoo, S. K., Sahoo, A. K., Yanine, F. F., \& Sukchai, S. 2020. Empirical Study on various Factors Influencing Green Business Practices. Proceedings of the 2020 International Conference on Renewable Energy Integration into Smart Grids: A Multidisciplinary Approach to Technology Modelling and Simulation, ICREISG 2020, 137-142. https://doi.org/10.1109/ICREISG49226.2020.917454 6

[27] Akehurst, G., Afonso, C., \& Gonçalves, H. M. 2012. Re-examining green purchase behaviour and the green consumer profile: New evidences. Management Decision, 50(5), 972-988.

[28] Mishal, A., Dubey, R., Gupta, O. K., \& Luo, Z. 2017. Dynamics of environmental consciousness and green purchase behaviour: an empirical study. International Journal of Climate Change Strategies and Management, 9(5), 682-706 https://doi.org/10.1108/IJCCSM-11-2016-0168

[29] Ursachi, G., Horodnic, I. A., \& Zait, A. 2015. How Reliable are Measurement Scales? External Factors with Indirect Influence on Reliability Estimators. Procedia Economics and Finance, 20(March), 679686. https://doi.org/10.1016/s2212-5671(15)00123-9

[30] Mohamad, M. M., Sulaiman, N. L., Sern, L. C., \& Salleh, K. M. 2015. Measuring the Validity and Reliability of Research Instruments. Procedia - Social and Behavioral Sciences, 204(January 2016), 164171. https://doi.org/10.1016/j.sbspro.2015.08.129

[31] Ogiemwonyi, O., Harun, A. Bin, Alam, M. N., Karim, A. M., Tabash, M. I., Hossain, M. I., Aziz, S., Abbasi, B. A., \& Ojuolape, M. A. 2020. Green product as a means of expressing green behaviour: A crosscultural empirical evidence from Malaysia and Nigeria. Environmental Technology and Innovation, 20, 101055. https://doi.org/10.1016/j.eti.2020.101055 